\title{
Pre-diagnostic serum levels of EGFR and ErbB2 and genetic glioma risk variants: a nested case-control study
}

\author{
Florentin Späth ${ }^{1,2}$ • Ulrika Andersson ${ }^{1,2}$ • Anna M. Dahlin ${ }^{1,2,3}$ • Hilde Langseth ${ }^{4}$. \\ Eivind Hovig ${ }^{5,6,7}$ • Tom Børge Johannesen ${ }^{4}$ - Kjell Grankvist ${ }^{8}$ - Benny Björkblom ${ }^{9}$. \\ Carl Wibom ${ }^{1,2,3} \cdot$ Beatrice Melin ${ }^{1,2}$
}

Received: 4 November 2015 / Accepted: 27 December 2015 / Published online: 23 February 2016

(C) The Author(s) 2016. This article is published with open access at Springerlink.com

\begin{abstract}
Genetic variants have been associated with the risk of developing glioma, but functional mechanisms on disease phenotypic traits remain to be investigated. One phenotypic trait of glioblastoma is the mutation and amplification of the epidermal growth factor receptor $(E G F R)$ gene. We investigated associations between pre-diagnostic serum protein concentrations of EGFR and ErbB2, both members of the EGFR family, and future risk of glioma. Further, we studied if $E G F R$ glioma risk variants were associated with EGFR and ErbB2 serum levels. We assessed the associations between genetic glioma risk variants and serum concentrations of EGFR and
\end{abstract}

Electronic supplementary material The online version of this article (doi:10.1007/s13277-015-4742-y) contains supplementary material, which is available to authorized users.

Florentin Späth

florentin.spaeth@umu.se

1 Department of Radiation Sciences, Umeå University, 901 87 Umeå, Sweden

2 Department of Oncology, Umeå University, 90187 Umeå, Sweden

3 Computational Life Science Cluster (CLiC), Umeå University, 901 87 Umeå, Sweden

4 Cancer Registry of Norway, Institute of Population-based Cancer Research, Oslo, Norway

5 Department of Informatics, University of Oslo, Oslo, Norway

6 Department of Tumor Biology, Institute for Cancer Research, Oslo University Hospital, Oslo, Norway

7 Institute for Cancer Genetics and Informatics, Oslo University Hospital, Oslo, Norway

8 Department of Medical Biosciences, Clinical Chemistry, Umeå University, 90185 Umeå, Sweden

9 Department of Chemistry, Umeå University, 90187 Umeå, Sweden
ErbB2, as measured in pre-diagnostic cohort serum samples of 593 glioma patients and 590 matched cancer-free controls. High serum EGFR and ErbB2 levels were associated with risk of developing glioblastoma $(P=0.008$; OR $=1.58,95 \%$ $\mathrm{CI}=1.13-2.22$ and $P=0.017, \mathrm{OR}=1.63,95 \% \mathrm{CI}=1.09$ 2.44, respectively). High serum ErbB2 concentration was also associated with glioma risk overall $(P=0.049 ; \mathrm{OR}=1.39$, $95 \% \mathrm{CI}=1.00-1.93)$. Glioma risk variants were not associated with high serum protein abundance. In contrast, the $E G F R$ risk variant rs4947986 $(T)$ was correlated with decreased EGFR serum levels (study cohort $P=0.024$ and controls $P=0.009$ ). To our knowledge, this is the first study showing an association of EGFR and ErbB2 serum levels with glioma more than a decade before diagnosis, indicating that EGFR and ErbB2 serum proteins are important in early gliomagenesis. However, we did not find evidence that glioma risk variants were associated with high pre-diagnostic serum concentrations of EGFR and ErbB2.

Keywords Glioma · SNP · Serum EGFR · Serum ErbB2 · Pre-diagnostic

\section{Introduction}

The incidence of gliomas is approximately six new diagnosed cases per 100,000 inhabitants per year [1]. The 5 -year survival rate for patients with glioblastomas has improved with combined chemoradiotherapy, but still most patients are not longterm survivors [2]. Curative treatment is rare due to the infiltrative growth of the tumor [3]. General cancer risk factors, such as alcohol and smoking, have not been associated with brain tumors [4] and currently there is no sufficient knowledge of the etiology of gliomas. Established glioma risk factors are ionizing radiation, hereditary syndromes, and increasing age, 
whereas asthma and allergy are inversely associated with the risk of developing gliomas [5, 6]. Increasing evidence supports a genetic component in glioma etiology, including both observations of familiar aggregation of gliomas [7-9] and observations of nine single nucleotide polymorphisms (SNPs) being associated with risk of developing gliomas, identified through large scale genome-wide association studies (GWAS) [10-14] (Table 1). Additional polymorphisms suggested to be associated with glioma risk include rs4947979 and rs4947986 at 7p11.2 (EGFR), identified by our group through a candidate gene approach [15] (Table 1). In another study, rs4947986 was associated with poor survival, although failing replication in a validation dataset [16].

$E G F R$ is mutated and amplified in up to $70 \%$ of primary glioblastomas [17, 18]. The EGFR family consists of four receptor tyrosine kinases: EGFR (ErbB1), Her2 (ErbB2), Her3 (ErbB3), and Her4 (ErbB4) [19]. EGFR family members are involved in many cellular processes, for example, cell proliferation and apoptosis, and are known to play a central role in development and progression in different types of cancer [20]. Deregulated EGFR signaling has been identified as a critical driver in glioblastoma tumor initiation and progression $[21,22]$. Structural studies revealed that the extracellular region of EGFR is induced to homo- or heterodimerize after growth factor binding resulting in an allosteric activation of the intracellular tyrosine kinase domain [23]. However, there are multiple mechanisms causing deregulated epidermal growth factor (EGF) receptor signaling in glioblastomas, such as (i) increased EGFR abundance through gene amplification and/or increased gene translation, (ii) increased abundance of EGFR through autocrine loops, and (iii) mutations rendering the receptor constitutively active [22].

$E G F R$ gene mutations are in the majority of glioblastomas accompanied by regional DNA amplification, leading to a higher number of copies of the mutated allele. The Cancer Genome Atlas (TCGA) consortium identified six somatic mutations in glioblastomas that affect EGFR protein structure,

Table 1 Genetic variants associated with glioma

\begin{tabular}{llll}
\hline $\mathrm{SNP}^{\mathrm{a}}$ & Locus & Gene & Reference \\
\hline $\mathbf{r s 4 2 9 5 6 2 7}$ & $8 \mathrm{q} 24.21$ & CCDC26 & {$[10]$} \\
$\mathbf{r s 4 9 8 8 7 2}$ & $11 \mathrm{q} 23.3$ & PHLDB1 & {$[10]$} \\
$\mathbf{r s 6 0 1 0 6 2 0}$ & $20 \mathrm{q} 13.33$ & RTEL1 & {$[10]$} \\
$\mathbf{r s 4 9 7 7 7 5 6}$ & $9 \mathrm{p} 21.3$ & $C D K N 2 B-A S 1$ & {$[10]$} \\
rs1412829 & $9 \mathrm{p} 21.3$ & CDKN2B-AS1 & {$[11]$} \\
$\mathbf{r s 2 2 5 2 5 8 6}$ & $7 \mathrm{p} 11.2$ & $E G F R$ & {$[12]$} \\
$\mathbf{r s 1 1 9 7 9 1 5 8}$ & $7 \mathrm{p} 11.2$ & $E G F R$ & {$[12]$} \\
$\mathbf{r s 7 8 3 7 8 2 2 2}$ & $17 \mathrm{p} 13.1$ & $T P 53$ & {$[13,14]$} \\
rs4947979 & $7 \mathrm{p} 11.2$ & $E G F R$ & {$[15]$} \\
rs4947986 & $7 \mathrm{p} 11.2$ & $E G F R$ & {$[15]$} \\
\hline
\end{tabular}

${ }^{a}$ Variants detected by means of GWAS in bold ranging from extracellular domain point mutations and deletions to deletions in the cytoplasmic tail of the receptor [24]. The aberrant exon 1-8 junction characteristic of EGFRvIII ( $\Delta$ e 2-7 vIII deletion) was highly expressed in some of the tumors investigated by TCGA. Although the biological or clinical relevance of EGFRvIII expression remains to be demonstrated, EGFRvIII expression in glioblastoma cells confers a more aggressive tumor phenotype [24, 25]. Three different $\mathrm{C}$-terminal rearrangements, targeting the cytoplasmic domain of EGFR, were also detected [24]. C-terminal deletion variants have been associated with gliomagenesis in experimental rodent systems in vivo [26]. Furthermore, two relatively uncharacterized recurrent $E G F R$ variants, deletions of exons $12-13(\Delta \mathrm{e} 12-13)$ and exons $14-15(\Delta \mathrm{e} 14-15)$ were identified by TCGA. Both $\Delta \mathrm{e} 12-13$ and $\Delta \mathrm{e} 14-15$ appear to be expressed in minor allelic fractions $(<10 \%)$, raising the question of whether they result from splicing aberration or genomic deletion [24]. This shows that somatic events in EGFR are common and complex and that studies of tumor heterogeneity assumes that it also is an early event as it was evident in all parts of the tumor [27].

The identified genetic risk variants for glioma are mostly mapping to intronic or intergenic parts of the genome, with no known function. To gain a better understanding of glioma etiology, the potential function of these variants requires further investigation. In this study, we investigated if there is a correlation between genetic glioma risk variants and levels of EGFR and ErbB2 in pre-diagnostic sera from glioma patients and matched controls. In particular, our investigation focused on four polymorphisms located in or close to the EGFR gene. The SNPs rs11979158 and rs4947979 are both located in intron 1, while rs4947986 maps to the intron-exon boundary in exon 6 or 7 of the EGFR gene, depending on the transcript. The fourth SNP in focus was rs2252586, which is located $107 \mathrm{~kb}$ downstream of $E G F R$.

\section{Materials and methods}

\section{Biological samples}

The study was designed as a nested case-control study within the Janus Serum Bank of Norway [28]. Detailed descriptions of the Janus repository and the present study population have been published recently [29]. In brief, we identified 593 glioma cases by linking the Janus cohort to the Cancer Registry of Norway. Cases were diagnosed on average 15 years after blood sample collection. A total of 590 cancer-free controls were individually matched on the basis of sex, year of birth (within 15 months), county, and date of sample collection (within 4 months). All pre-diagnostic serum samples were donated between 1972 and 2004 and stored at $-25^{\circ} \mathrm{C}$ at the Janus repository. Most of the samples came from people in 
their forties undergoing health surveys of cardiovascular disease risk. Health examination samples collected between 1974 and 1978 were collected in vacutainer tubes containing $5 \mathrm{mg}$ iodoacetate $(n=388)$. Around $10 \%$ of the samples of the Janus cohort were collected from Red Cross Blood Bank donors. Red Cross blood donor samples collected between 1973 and 1975 were lyophilized $(n=75)$. All other samples underwent no special procedures after collection. The study was approved by the ethical review board at the University of Oslo, Norway.

\section{DNA amplification}

Five-microliter aliquots of serum were transferred into 96-well microplates (Axygen, VWR, Oslo, Norway) and subjected to enzymatic amplification, as described by Ekstrøm et al. [30]. Serum aliquots were denatured and PCR master mix was added to each well, and plates were subjected to temperature cycling as described [29].

\section{Variant detection}

Amplified 6-FAM (6-carboxyfluorescein, single isomer) labeled PCR products were analyzed by denaturant capillary electrophoresis on a MegaBACE 1000 DNA Analysis System (GE Healthcare Bio-Sciences AB, Uppsala, Sweden). The base variants were separated by cycling temperature capillary electrophoresis (CTCE), with separating temperatures. The variants were identified by co-analysis with a mutated internal standard, essentially as described by Bjørheim et al. [31]. The assay was run in a 96-well format, where a minimum of two wells per microplate were used for controls, i.e. one serum control (pool of sera from five healthy individuals) and at least one negative control without serum template. The genetic variants analyzed were selected from previous GWAS and candidate genes including rs11979158, rs2252586, rs4947979, rs4947986 (all EGFR), rs1412829, rs4977756 (both $C D K N 2 B-A S 1$ ), rs2736100 (TERT), rs4295627 (CCDC26), rs498872 (PHLDB1), rs6010620 (RTEL1), rs78378222 (TP53), and rs1476278 (PGAP3) (Tables 3 and 4), as described by Wibom et al. [29].

\section{EGFR and ErbB2 serum detection}

EGFR and ErbB2 serum levels were measured by a multiplex immunoassay (Meso Scale Discovery (MSD), Gaithersburg, MD, USA) according to the manufacturer's protocol. MultiSpot $^{\circledR}$ 96-well plates from MSD were coated by the manufacturer with two different antigens to capture antibodies against EGFR and ErbB2 in human serum samples. All Multi-Spot ${ }^{\circledR}$ 96-well plates were ordered in a single lot to reduce interassay variation. Reagents used for the multiplex immunoassay were from MSD, if not stated separately. Recombinant human
EGFR (R\&D Systems Europe Ltd, Oxon, UK) and ErbB2 (eBioscience, Inc. CA, USA) were diluted in diluent 9 to prepare a calibration mix for the standard curves. Each well in the antigen-coated plates were incubated with $150 \mu$ l blocking solution $\mathrm{C}$ at room temperature for $1 \mathrm{~h}$ with shaking and washed three times with phosphate-buffered saline containing $0.05 \%$ Tween 20 (PBS-T). Diluent 7 were added to each well and thereafter $25 \mu$ of calibrator mix, internal controls, or samples were added to each well. The plates were sealed and incubated at room temperature for $2 \mathrm{~h}$ on a shaker and then washed three times with PBS-T. After that $25 \mu \mathrm{l}$ multiplex detection antibody mix (containing Sulfo-Tag-labeled secondary antibodies against EGFR and ErbB2, Sulfo-Taglabeled streptavidin, D-R blocker, D-M blocker, and diluent 8 ) was added. The plates were sealed and incubated at room temperature for $2 \mathrm{~h}$ on a shaker and then washed three times in PBS-T. Finally, $150 \mu \mathrm{l}$ of MSD Read Buffer-T was added to each well. Quantification of protein concentrations was performed with MSD sector imager model no. 2400. Each analyzed assay plate included, a standard curve, case-control samples (blinded and placed in random order), and two laboratory control samples allowing to monitor inter-assay variation.

\section{Quality control}

The quality of the genotype data was assessed by calculating call rates for both samples and genotypes. Samples that displayed a genotyping call rate of $<80 \%$ (i.e., where the genotyping had failed at $>2$ variants) were removed from further analyses involving genotype data. We also tested the genotype frequency distribution among controls for each SNP against the Hardy-Weinberg equilibrium (HWE) to identify potential genotyping errors. Among the serum protein abundance data, values outside mean \pm 5 standard deviations were removed as outliers.

\section{Statistical analysis}

To investigate associations between protein abundance in serum and risk of disease, we applied conditional logistic regression both to untransformed continuous abundance data and to dichotomized abundance data, where the median of the control population (EGFR $57.517 \mathrm{ng} / \mathrm{ml}$; ErbB2 $1.857 \mathrm{ng} / \mathrm{ml}$ ) was used as cutoff for categorization. To investigate correlations between protein abundance in serum and a given genotype, we applied an additive linear regression model (as the samples were not matched for these analyses) and included the following covariates: sex, storage time, sample lyophilization, addition of iodoacetate, and analysis batch. We performed separate analyses for the following groups: all cases, cases with blood sample donation within 5 years to diagnosis, glioblastomas, oligodendrogliomas, astrocytomas, controls, and 
the entire study cohort. All analyses were performed using the $\mathrm{R}$ software for statistical computing (www.R-project.org).

\section{Results}

Genotyping was successful for 1178 of 1183 samples. All included variants displayed a call rate of $>90 \%$ and a HWE $P$ value $>0.005$, i.e., there was no indication of genotyping errors. The quantification of serum levels of EGFR and ErbB2 was successful in all but five instances. One sample failed for both EGFR and ErbB2, and the ErbB2 values from three additional samples were removed as outliers.

The characteristics of the study population are represented in Table 2. Time from blood sample collection to case diagnosis was 14.7 years (median) and ranged from 2 months to 35 years. We found no evidence for a correlation between

Table 2 Characteristics of the study population

\begin{tabular}{|c|c|c|c|c|}
\hline & \multicolumn{2}{|c|}{ Cases } & \multicolumn{2}{|c|}{ Controls $^{\mathrm{a}}$} \\
\hline & $N$ & $\%$ & $N$ & $\%$ \\
\hline & 593 & 100 & 590 & 100 \\
\hline \multicolumn{5}{|l|}{ Sex } \\
\hline Female & 199 & 33.6 & 198 & 33.6 \\
\hline Male & 394 & 66.4 & 392 & 66.4 \\
\hline \multicolumn{5}{|l|}{ Age at sampling (years) } \\
\hline $18-30$ & 53 & 8.9 & 55 & 9.3 \\
\hline $31-40$ & 220 & 37.1 & 213 & 36.1 \\
\hline $41-50$ & 295 & 49.8 & 296 & 50.2 \\
\hline $51-60$ & 8 & 1.3 & 9 & 1.5 \\
\hline $61-70$ & 16 & 2.7 & 15 & 2.6 \\
\hline $71-75$ & 1 & 0.2 & 2 & 0.3 \\
\hline \multicolumn{5}{|l|}{ Year of sampling } \\
\hline $1972-1985$ & 283 & 47.7 & 280 & 47.5 \\
\hline 1986-1991 & 246 & 41.5 & 248 & 42.0 \\
\hline 1992-1997 & 60 & 10.1 & 58 & 9.8 \\
\hline 1998-2003 & 4 & 0.7 & 4 & 0.7 \\
\hline \multicolumn{5}{|l|}{ Histologic subtypes } \\
\hline Glioblastoma & 396 & 66.8 & & \\
\hline Oligodendroglioma & 33 & 5.6 & & \\
\hline Ependymoma & 27 & 4.5 & & \\
\hline Astrocytoma & 94 & 15.9 & & \\
\hline Other subtypes & 43 & 7.2 & & \\
\hline \multicolumn{5}{|c|}{ Time from sampling to diagnosis } \\
\hline Mean \pm SD (years) & \multicolumn{2}{|c|}{$15.2 \pm 8.6$} & & \\
\hline \multicolumn{5}{|c|}{ Median serum protein level } \\
\hline EGFR (ng/ml) & \multicolumn{2}{|c|}{58.35} & \multicolumn{2}{|l|}{57.52} \\
\hline ErbB2 (ng/ml) & \multicolumn{2}{|l|}{1.95} & \multicolumn{2}{|l|}{1.86} \\
\hline
\end{tabular}

${ }^{\text {a }}$ Controls were matched to cases on sex, age ( \pm 15 months), and date of sample collection ( \pm 4 months) serum levels of neither EGFR nor ErbB2 and time between sampling and diagnosis, $P=0.499$ and $P=0.221$ respectively. EGFR levels appeared to increase in correlation with storage time ( $P=0.014)$, as assessed by linear regression adjusted for sex, analysis batch variation, addition of iodoacetate, and sample lyophilization. We noticed a similar trend for ErbB2 levels, although not significant $(P=0.279)$. By the same analysis approach, both EGFR and ErbB2 were found having higher levels in males than in females $\left(P=4.625 \times 10^{-6}\right.$ and $P=1.960 \times 10^{-6}$ respectively).

We assessed the associations between serum protein concentrations and disease risk (overall and by histological subtype) using both untransformed continuous abundance data and dichotomized abundance data. By dichotomizing the abundance variables, we found an association between high pre-diagnostic EGFR concentration and risk of glioblastoma $(P=0.008$; OR $=1.58,95 \% \mathrm{CI}=1.13-2.22)$, as well as associations between high pre-diagnostic ErbB2 concentration and overall risk for glioma $(P=0.049 ; \mathrm{OR}=1.39,95 \% \mathrm{CI}=1.00$ $1.93)$ and glioblastoma $(P=0.017, \mathrm{OR}=1.63,95 \%$ $\mathrm{CI}=1.09-2.44)$. We could not confirm these observations when investigating continuous abundance data and glioma risk (all $P>0.05$ ). Median serum protein concentrations are shown for cases and controls in Table 2. Density plots were applied to visualize continuous distributions of serum protein levels for cases and controls (Supplementary figure 1).

Possible correlations between risk SNPs and serum levels of EGFR and ErbB2 were analyzed. The analyses were performed separately for overall glioma cases, glioma subtypes, control individuals, and the entire study cohort, including both cases and controls. All results are listed in Tables 3 and 4.

Among the EGFR gene variants included in the study, we found a correlation between rs4947986 and decreased EGFR serum levels $(P=0.024)$, as observed in the entire study cohort. The association seemed accentuated among controls $(P=0.009)$. Similar trends were observed in major histologic subtypes investigated, albeit not statistically significant $(P>0.05)$. Another $E G F R$ gene variant, rs4947979, correlated with lower EGFR concentration in oligodendroglioma cases $(P=0.050)$.

The weak correlations between risk variants of $C C D C 26$, $P G A P 3$, and $P H L D B 1$ and serum protein concentration, which were not corresponding to our predefined hypothesis, are even presented in Tables 3 and 4 .

None of the described correlations of genotypes with serum protein levels were significant after adjusting for multiple testing.

\section{Discussion}

Numerous studies have found an association between the expression of EGFR and its heterodimerization partner ErbB2 
Table 3 Trends for EGFR serum levels for glioma subtypes and controls depending on genotype

\begin{tabular}{|c|c|c|c|c|c|c|c|c|c|c|}
\hline SNP & Gene & $\begin{array}{l}\text { Alleles } \\
\text { Major| Minor }\end{array}$ & Cases & Glioma & GBM & Oligo & Astro & $\begin{array}{l}\text { Cases }^{\mathrm{a}} \\
<5 \text { years }\end{array}$ & Controls & Study-cohort \\
\hline \multirow[t]{2}{*}{ rs11979158 } & $E G F R$ & $\mathrm{~T} \mid \mathrm{C}$ & ns & ns & ns & ns & ns & ns & ns & ns \\
\hline & & & $\uparrow$ & $\uparrow$ & $\uparrow$ & $\downarrow$ & $\downarrow$ & $\uparrow$ & $\downarrow$ & $\uparrow$ \\
\hline \multirow[t]{2}{*}{ rs1412829 } & $C D K N 2 B$ & $\mathrm{~T} \mid \mathbf{C}$ & ns & ns & ns & ns & ns & ns & ns & ns \\
\hline & & & $\uparrow$ & $\uparrow$ & $\uparrow$ & $\downarrow$ & $\downarrow$ & $\uparrow$ & $\downarrow$ & $\uparrow$ \\
\hline \multirow[t]{2}{*}{ rs1476278 } & $P G A P 3$ & $\mathrm{C} \mid \mathbf{T}$ & $\mathrm{ns}$ & $\mathrm{ns}$ & ns & ns & ns & ns & ns & $\mathrm{ns}$ \\
\hline & & & $\downarrow$ & $\downarrow$ & $\uparrow$ & $\downarrow$ & $\downarrow$ & $\uparrow$ & $\downarrow$ & $\downarrow$ \\
\hline \multirow[t]{2}{*}{ rs2252586 } & $E G F R$ & $\mathrm{C} \mid \mathbf{T}$ & ns & ns & ns & ns & ns & ns & ns & ns \\
\hline & & & $\downarrow$ & $\downarrow$ & $\downarrow$ & $\uparrow$ & $\uparrow$ & $\uparrow$ & $\downarrow$ & $\downarrow$ \\
\hline \multirow[t]{2}{*}{ rs2736100 } & $T E R T$ & $\mathbf{G} \mid \mathrm{T}$ & $\mathrm{ns}$ & $\mathrm{ns}$ & ns & ns & ns & ns & $\mathrm{ns}$ & ns \\
\hline & & & $\uparrow$ & $\uparrow$ & $\uparrow$ & $\uparrow$ & $\downarrow$ & $\uparrow$ & $\uparrow$ & $\uparrow$ \\
\hline \multirow[t]{2}{*}{ rs4295627 } & $C C D C 26$ & $\mathrm{~T} \mid \mathbf{G}$ & $\mathrm{ns}$ & ns & ns & ns & ns & 0.03 & $\mathrm{~ns}$ & ns \\
\hline & & & $\uparrow$ & $\uparrow$ & $\uparrow$ & $\downarrow$ & $\uparrow$ & $\uparrow$ & $\uparrow$ & $\uparrow$ \\
\hline \multirow[t]{2}{*}{ rs4947979 } & $E G F R$ & $\mathbf{A} \mid \mathrm{G}$ & $\mathrm{ns}$ & $\mathrm{ns}$ & ns & 0.05 & ns & ns & $\mathrm{ns}$ & ns \\
\hline & & & $\downarrow$ & $\downarrow$ & $\downarrow$ & $\downarrow$ & $\uparrow$ & $\uparrow$ & $\downarrow$ & $\downarrow$ \\
\hline \multirow[t]{2}{*}{ rs4947986 } & $E G F R$ & $\mathrm{C} \mid \mathbf{T}$ & ns & ns & ns & ns & ns & ns & 0.009 & 0.02 \\
\hline & & & $\downarrow$ & $\downarrow$ & $\downarrow$ & $\downarrow$ & $\downarrow$ & $\uparrow$ & $\downarrow$ & $\downarrow$ \\
\hline \multirow[t]{2}{*}{ rs4977756 } & $C D K N 2 A / 2 B$ & $\mathrm{~A} \mid \mathbf{G}$ & ns & ns & ns & ns & $\mathrm{ns}$ & $\mathrm{ns}$ & ns & ns \\
\hline & & & $\uparrow$ & $\uparrow$ & $\uparrow$ & $\uparrow$ & $\downarrow$ & $\uparrow$ & $\downarrow$ & $\downarrow$ \\
\hline \multirow[t]{2}{*}{ rs498872 } & PHLDB1 & $\mathrm{G} \mid \mathbf{A}$ & ns & $\mathrm{ns}$ & $\mathrm{ns}$ & ns & ns & $\mathrm{ns}$ & $\mathrm{ns}$ & ns \\
\hline & & & $\downarrow$ & $\uparrow$ & $\uparrow$ & $\uparrow$ & $\downarrow$ & $\downarrow$ & $\downarrow$ & $\downarrow$ \\
\hline \multirow[t]{2}{*}{ rs6010620 } & RTEL1 & $\mathbf{G} \mid \mathrm{A}$ & $\mathrm{ns}$ & ns & ns & ns & ns & ns & $\mathrm{ns}$ & ns \\
\hline & & & $\downarrow$ & $\downarrow$ & $\downarrow$ & $\uparrow$ & $\uparrow$ & $\uparrow$ & $\downarrow$ & $\downarrow$ \\
\hline \multirow[t]{2}{*}{ rs78378222 } & TP53 & $\mathrm{A} \mid \mathbf{C}$ & $\mathrm{ns}$ & $\mathrm{ns}$ & $\mathrm{ns}$ & nd & $\mathrm{ns}$ & nd & $\mathrm{ns}$ & ns \\
\hline & & & $\downarrow$ & $\downarrow$ & $\downarrow$ & & $\downarrow$ & & $\uparrow$ & $\downarrow$ \\
\hline
\end{tabular}

Arrows indicate higher $(\uparrow)$ or lower $(\downarrow)$ serum EGFR for the risk allele (significant trends and risk allele in bold)

$n s$ not significant, $n d$ not determined, GBM glioblastoma, Oligo oligodendroglioma, Astro astrocytoma

${ }^{\text {a }}$ Cases with sample donation $0-5$ years before diagnosis

within different tumors [32-34], including gliomas [35-37]. Identifying nine glioma susceptibility loci, GWA studies have provided further information about glioma etiology, although it is unclear how these risk variants initiate pathogenic effects. This missing information offered a compelling rationale for our study: we investigated potential associations between known glioma risk variants and pre-diagnostic serum levels of EGFR and ErbB2. In addition, we evaluated the association between the risk for glioma and pre-diagnostic serum levels of EGFR and ErbB2 using both dichotomized and continuous protein abundance data to understand if chronic activation and high levels of the receptors could be a mechanism in gliomagenesis. By dichotomizing pre-diagnostic serum protein concentration according to the median of the control population, we found that both high levels of EGFR and ErbB2 were associated with glioblastoma risk. High serum concentration of ErbB2 was also associated with glioma risk overall. A chance finding cannot be ruled out, as the correlations were not evident when analyzing continuous data. It is possible, however, that specific cutoff values need to be exceeded to initiate gliomagenesis, a phenomena that has been observed for high levels of pre-diagnostic C-reactive protein and the genesis of ovarian cancer [38].

To our knowledge, pre-diagnostic serum EGFR and ErbB2 concentrations have not been studied in glioma, although it is known that elevated serum EGFR in samples taken at glioma diagnosis is associated with worse prognosis [39]. In our study, the long lag time (almost 15 years) between sample donation and glioblastoma diagnosis indicates that increased serum EGFR and ErbB2 are likely to be associated with an etiological factor more than with the effects of undiagnosed disease (i.e., reverse causation). Given that the blood-brain barrier is expected to be intact such a long time before diagnosis, it might be speculated that the observed serum protein perturbations may take their origin outside of the central nervous system (e.g., due to environmental factors). Elevated serum protein abundance could be a tumor-initiating factor as, for example, is the case for chronic inflammation due to hepatitis $\mathrm{C}$ which can precede liver cancer and lymphoma [40]. 
Table 4 Trends for ErbB2 serum levels for glioma subtypes and controls depending on genotype

\begin{tabular}{|c|c|c|c|c|c|c|c|c|c|c|}
\hline SNP & Gene & $\begin{array}{l}\text { Alleles } \\
\text { Major| Minor }\end{array}$ & Cases & Glioma & GBM & Oligo & Astro & $\begin{array}{l}\text { Cases }^{\mathrm{a}} \\
<5 \text { years }\end{array}$ & Controls & Study-cohort \\
\hline \multirow[t]{2}{*}{ rs11979158 } & $E G F R$ & $\mathrm{~T} \mid \mathrm{C}$ & ns & ns & ns & ns & ns & ns & ns & ns \\
\hline & & & $\uparrow$ & $\uparrow$ & $\uparrow$ & $\uparrow$ & $\uparrow$ & $\downarrow$ & $\downarrow$ & $\uparrow$ \\
\hline \multirow[t]{2}{*}{ rs1412829 } & $C D K N 2 B$ & $\mathrm{~T} \mid \mathbf{C}$ & & ns & ns & ns & ns & ns & ns & ns \\
\hline & & & $\uparrow$ & $\uparrow$ & $\uparrow$ & $\downarrow$ & $\uparrow$ & $\uparrow$ & $\uparrow$ & $\uparrow$ \\
\hline \multirow[t]{2}{*}{ rs1476278 } & $P G A P 3$ & $\mathrm{C} \mid \mathbf{T}$ & $\mathrm{ns}$ & $\mathrm{ns}$ & ns & 0.05 & 0.05 & ns & ns & $\mathrm{ns}$ \\
\hline & & & $\downarrow$ & $\downarrow$ & $\downarrow$ & $\downarrow$ & $\downarrow$ & $\uparrow$ & $\downarrow$ & $\downarrow$ \\
\hline \multirow[t]{2}{*}{ rs2252586 } & $E G F R$ & $\mathrm{C} \mid \mathbf{T}$ & ns & ns & ns & ns & ns & ns & ns & ns \\
\hline & & & $\downarrow$ & $\downarrow$ & $\downarrow$ & $\downarrow$ & $\downarrow$ & $\downarrow$ & $\downarrow$ & $\downarrow$ \\
\hline \multirow[t]{2}{*}{ rs2736100 } & $T E R T$ & $\mathbf{G} \mid \mathrm{T}$ & $\mathrm{ns}$ & $\mathrm{ns}$ & ns & ns & ns & ns & $\mathrm{ns}$ & ns \\
\hline & & & $\uparrow$ & $\downarrow$ & $\downarrow$ & $\downarrow$ & $\uparrow$ & $\uparrow$ & $\uparrow$ & $\uparrow$ \\
\hline \multirow[t]{2}{*}{ rs4295627 } & $C C D C 26$ & $\mathrm{~T} \mid \mathbf{G}$ & $\mathrm{ns}$ & $\mathrm{ns}$ & ns & ns & ns & ns & $\mathrm{ns}$ & ns \\
\hline & & & $\uparrow$ & $\uparrow$ & $\uparrow$ & $\downarrow$ & $\downarrow$ & $\uparrow$ & $\downarrow$ & $\downarrow$ \\
\hline \multirow[t]{2}{*}{ rs4947979 } & $E G F R$ & $\mathbf{A} \mid \mathrm{G}$ & $\mathrm{ns}$ & $\mathrm{ns}$ & ns & ns & ns & ns & $\mathrm{ns}$ & ns \\
\hline & & & $\uparrow$ & $\uparrow$ & $\uparrow$ & $\downarrow$ & $\downarrow$ & $\uparrow$ & $\uparrow$ & $\uparrow$ \\
\hline \multirow[t]{2}{*}{ rs4947986 } & $E G F R$ & $\mathrm{C} \mid \mathbf{T}$ & $\mathrm{ns}$ & $\mathrm{ns}$ & ns & $\mathrm{ns}$ & $\mathrm{ns}$ & ns & ns & ns \\
\hline & & & $\uparrow$ & $\uparrow$ & $\uparrow$ & $\uparrow$ & $\downarrow$ & $\uparrow$ & $\downarrow$ & $\downarrow$ \\
\hline \multirow[t]{2}{*}{ rs4977756 } & $C D K N 2 A / 2 B$ & $\mathrm{~A} \mid \mathbf{G}$ & ns & ns & ns & ns & $\mathrm{ns}$ & $\mathrm{ns}$ & ns & ns \\
\hline & & & $\uparrow$ & $\uparrow$ & $\uparrow$ & $\downarrow$ & $\uparrow$ & $\uparrow$ & $\uparrow$ & $\uparrow$ \\
\hline \multirow[t]{2}{*}{ rs498872 } & PHLDB1 & $\mathrm{G} \mid \mathbf{A}$ & $\mathrm{ns}$ & $\mathrm{ns}$ & $\mathrm{ns}$ & ns & ns & 0.005 & $\mathrm{~ns}$ & ns \\
\hline & & & $\downarrow$ & $\downarrow$ & $\downarrow$ & $\downarrow$ & $\downarrow$ & $\downarrow$ & $\uparrow$ & $\downarrow$ \\
\hline \multirow[t]{2}{*}{ rs6010620 } & RTEL1 & $\mathbf{G} \mid \mathrm{A}$ & $\mathrm{ns}$ & ns & ns & ns & ns & ns & ns & ns \\
\hline & & & $\uparrow$ & $\uparrow$ & $\uparrow$ & $\uparrow$ & $\downarrow$ & $\uparrow$ & $\downarrow$ & $\downarrow$ \\
\hline \multirow[t]{2}{*}{ rs78378222 } & TP53 & $\mathrm{A} \mid \mathbf{C}$ & $\mathrm{ns}$ & $\mathrm{ns}$ & $\mathrm{ns}$ & nd & $\mathrm{ns}$ & nd & $\mathrm{ns}$ & ns \\
\hline & & & $\downarrow$ & $\downarrow$ & $\downarrow$ & & $\uparrow$ & & $\downarrow$ & $\downarrow$ \\
\hline
\end{tabular}

Arrows indicate higher $(\uparrow)$ or lower $(\downarrow)$ serum ErbB2 concentration for the risk allele (significant trends and risk allele in bold)

$n s$ not significant, $n d$ not determined, GBM glioblastoma, Oligo oligodendroglioma, Astro astrocytoma

${ }^{\text {a }}$ Cases with sample donation $0-5$ years before diagnosis

Both EGFR and ErbB2 serum levels displayed no detectable correlation with time between sampling and diagnosis. Because we did not have access to repeated pre-diagnostic samples, we could not dismiss concentration changes over time on the individual level. Ligand-mediated chronic activation of EGFR is necessary for gliomagenesis in mice [41], and this association might be consistent with our finding of time-stable, elevated serum EGFR and ErbB2 levels in glioblastomas. The mechanisms behind enhanced oncogenic signaling due to EGFR are extremely complex. For example, the activation of autocrine loops due to EGF ligands causes constitutive receptor activation [22]. Taking this process into account would have improved our study, but a broader screening of serum protein levels was not possible due to the limited volume of sera. However, EGFR activation and EGFR serum levels differ biologically: EGFR activation is an intracellular process, and serum levels of EGFR reflect extracellular protein concentrations.

There is high haplotype variability in the EGFR gene, and we analyzed a limited set of four polymorphisms, where one of them showed an association with lower serum EGFR. All four investigated genetic variants are independent of each other in terms of linkage disequilibrium. The underlying mechanisms connecting the observed association between genotype and serum levels are not clear. The polymorphism rs4947986 is located 47 bases from the boundary of exon 7 that is part of the extracellular domain II which is critical to EGFR dimerization $[23,42]$. It is plausible that it is linked with a, hitherto unidentified, variant that in turn affects the protein sequence. Considering the genomic location, changes to the protein sequence or structure may have large effects on the protein's physical properties, potentially affecting dimerization. Further understanding of the interactions between genetic variants and associations with haplotypes would require a fine mapping of the EGFR region in pre-diagnostic samples from other cohorts. In addition, matched blood and tumor samples with information regarding the exact type of somatic $E G F R$ mutations would help classify more specific subgroups and enable identification of stronger associations.

Our study had some limitations. All genotype-phenotype associations we present here were not significant following 
adjustment to both the family-wise error rate (Bonferroni correction) and the false discovery rate (Benjamini-Hochberg procedure). Both procedures to adjust for multiple testing might be too stringent and imply the risk of false-negative findings because some investigated variables are not independent and due to the experimental design and the hypothesis-driven character of our study. Another limitation concerns EGFR variants rs4947979 and rs4947986. These variants were suggested to be associated with gliomas by a candidate gene approach that included 728 glioma individuals [15]. Recently, our group found that both SNPs may primarily be associated with prolonged survival rather than with risk in 598 glioma cases [29]. However, the two variants might be important to the mutation cascade occurring in EGFR during glioma tumorigenesis.

Our data provide first evidence that increased serum EGFR and ErbB2 levels can be detected in glioblastoma patients more than a decade before diagnosis, indicating that both proteins are important early in gliomagenesis. To confirm these results, we will need broader collaborations with other centers that collect longitudinal data using similar approaches. Further studies of EGFR and gene-environment interaction will be performed in existing and recently collected case-control studies (Amirian et al., unpublished manuscript) to understand the interaction between genetic variants and environmental factors such as asthma, allergy, and smoking.

\section{Compliance with ethical standards}

Funding This study was supported by Acta Oncologica foundation through the Royal Swedish Academy of Science (BM salary), The Swedish Research Council, Swedish Cancer foundation, Northern Sweden Cancer foundation, Umeå University Young investigator reward, and Umeå Hospital cutting edge grant.

\section{Conflicts of interest None}

Ethical approval All procedures involving human participants were in accordance with the ethical standards of the institutional and national research committee and with the 1964 Helsinki declaration and its later amendments or comparable ethical standards.

Open Access This article is distributed under the terms of the Creative Commons Attribution 4.0 International License (http:// creativecommons.org/licenses/by/4.0/), which permits unrestricted use, distribution, and reproduction in any medium, provided you give appropriate credit to the original author(s) and the source, provide a link to the Creative Commons license, and indicate if changes were made.

\section{References}

1. Dolecek TA, Propp JM, Stroup NE, Kruchko C. CBTRUS statistical report: primary brain and central nervous system tumors diagnosed in the United States in 2005-2009. Neuro Oncol. 2012;14 suppl 5:v1-v49. doi:10.1093/neuonc/nos218.
2. Asklund T, Malmström A, Bergqvist M, Björ O, Henriksson R. Brain tumors in Sweden: data from a population-based registry 1999-2012. Acta Oncol. 2015;54(3):377-84. doi:10.3109/ 0284186X.2014.975369.

3. Butowski NA, Sneed PK, Chang SM. Diagnosis and treatment of recurrent high-grade astrocytoma. J Clin Oncol. 2006;24(8):127380. doi:10.1200/jco.2005.04.7522.

4. Braganza MZ, Rajaraman P, Park Y, Inskip PD, Freedman ND, Hollenbeck AR, et al. Cigarette smoking, alcohol intake, and risk of glioma in the NIH-AARP Diet and Health Study. Br J Cancer. 2014;110(1):242-8. doi:10.1038/bjc.2013.611.

5. Bondy ML, Scheurer ME, Malmer B, Barnholtz-Sloan JS, Davis FG, Il'yasova D, et al. Brain tumor epidemiology: consensus from the Brain Tumor Epidemiology Consortium. Cancer. 2008;113(S7): 1953-68. doi:10.1002/cncr.23741.

6. Schwartzbaum J, Ding B, Johannesen TB, Osnes LTN, Karavodin L, Ahlbom A, et al. Association between prediagnostic IgE levels and risk of glioma. J Natl Cancer Inst. 2012;104(16):1251-9. doi: 10.1093/jnci/djs315.

7. Malmer B, Henriksson R, Grönberg H. Familial brain tumoursgenetics or environment? A nationwide cohort study of cancer risk in spouses and first-degree relatives of brain tumour patients. Int $\mathrm{J}$ Cancer. 2003;106(2):260-3. doi:10.1002/ijc.11213.

8. Scheurer ME, Etzel CJ, Liu M, El-Zein R, Airewele GE, Malmer B, et al. Aggregation of cancer in first-degree relatives of patients with glioma. Cancer Epidemiol Biomarkers Prev. 2007;16(11):2491-5. doi:10.1158/1055-9965.epi-07-0576.

9. Wrensch M, Lee M, Miike R, Newman B, Bargar G, Davis R, et al. Familial and personal medical history of cancer and nervous system conditions among adults with glioma and controls. Am J Epidemiol. 1997;145(7):581-93.

10. Shete S, Hosking FJ, Robertson LB, Dobbins SE, Sanson M, Malmer B, et al. Genome-wide association study identifies five susceptibility loci for glioma. Nat Genet. 2009;41(8):899-904. http://www.nature.com/ng/journal/v41/n8/suppinfo/ng.407_S1. html.

11. Wrensch M, Jenkins RB, Chang JS, Yeh R-F, Xiao Y, Decker PA, et al. Variants in the CDKN2B and RTEL1 regions are associated with high-grade glioma susceptibility. Nat Genet. 2009;41(8):9058. http://www.nature.com/ng/journal/v41/n8/suppinfo/ng.408_S1. html.

12. Sanson M, Hosking FJ, Shete S, Zelenika D, Dobbins SE, Ma Y, et al. Chromosome 7p11.2 (EGFR) variation influences glioma risk. Hum Mol Genet. 2011;20(14):2897-904. doi:10.1093/hmg/ ddr192.

13. Enciso-Mora V, Hosking FJ, Di Stefano AL, Zelenika D, Shete S, Broderick P, et al. Low penetrance susceptibility to glioma is caused by the TP53 variant rs 78378222. Br J Cancer. 2013;108(10):217885. doi:10.1038/bjc.2013.155.

14. Stacey SN, Sulem P, Jonasdottir A, Masson G, Gudmundsson J, Gudbjartsson DF, et al. A germline variant in the TP53 polyadenylation signal confers cancer susceptibility. Nat Genet. 2011;43(11):1098-103. http:/www.nature.com/ng/journal/v43/ n11/abs/ng.926.html\#supplementary-information.

15. Andersson U, Schwartzbaum J, Wiklund F, Sjöström S, Liu Y, Tsavachidis $\mathrm{S}$, et al. A comprehensive study of the association between the EGFR and ERBB2 genes and glioma risk. Acta Oncol. 2010;49(6):767-75. doi:10.3109/0284186X.2010.480980.

16. Sjöström S, Andersson U, Liu Y, Brännström T, Broholm H, Johansen C, et al. Genetic variations in EGF and EGFR and glioblastoma outcome. Neuro Oncol. 2010;12(8):815-21. doi:10.1093/ neuonc/noq018.

17. Ekstrand AJ, Sugawa N, James CD, Collins VP. Amplified and rearranged epidermal growth factor receptor genes in human glioblastomas reveal deletions of sequences encoding portions of the N- 
and/or C-terminal tails. Proc Natl Acad Sci. 1992;89(10):4309-13. doi:10.1073/pnas.89.10.4309.

18. Ohgaki H, Dessen P, Jourde B, Horstmann S, Nishikawa T, Di Patre P-L, et al. Genetic pathways to glioblastoma: a population-based study. Cancer Res. 2004;64(19):6892-9. doi:10.1158/0008-5472. can-04-1337.

19. Pan D, Lin X. Epithelial growth factor receptor-activated nuclear factor [kappa]B signaling and its role in epithelial growth factor receptor-associated tumors. Cancer J. 2013;19(6):461-7. doi:10. 1097/PPO.0000000000000001.

20. Roskoski Jr R. The ErbB/HER family of protein-tyrosine kinases and cancer. Pharmacol Res. 2014;79(0):34-74. doi:10.1016/j.phrs. 2013.11.002.

21. Zhu H, Acquaviva J, Ramachandran P, Boskovitz A, Woolfenden $\mathrm{S}$, Pfannl R, et al. Oncogenic EGFR signaling cooperates with loss of tumor suppressor gene functions in gliomagenesis. Proc Natl Acad Sci. 2009;106(8):2712-6. doi:10.1073/pnas.0813314106.

22. Huang PH, Xu AM, White FM. Oncogenic EGFR signaling networks in glioma. vol 87. 2009.

23. Lemmon MA, Schlessinger J, Ferguson KM. The EGFR family: not so prototypical receptor tyrosine kinases. Cold Spring Harb Perspect Biol. 2014;6(4). doi:10.1101/cshperspect.a020768.

24. Brennan Cameron W, Verhaak Roel GW, McKenna A, Campos B, Noushmehr H, Salama Sofie R, et al. The somatic genomic landscape of glioblastoma. Cell. 2013;155(2):462-77. doi:10.1016/j. cell.2013.09.034.

25. Inda M-d-M, Bonavia R, Mukasa A, Narita Y, Sah DWY, Vandenberg $\mathrm{S}$, et al. Tumor heterogeneity is an active process maintained by a mutant EGFR-induced cytokine circuit in glioblastoma. Genes Dev. 2010;24(16):1731-45. doi:10.1101/gad.1890510.

26. Cho J, Pastorino S, Zeng Q, Xu X, Johnson W, Vandenberg S, et al. Glioblastoma-derived epidermal growth factor receptor carboxylterminal deletion mutants are transforming and are sensitive to EGFR-directed therapies. Cancer Res. 2011;71(24):7587-96. doi: 10.1158/0008-5472.can-11-0821.

27. Sottoriva A, Spiteri I, Piccirillo SGM, Touloumis A, Collins VP, Marioni JC, et al. Intratumor heterogeneity in human glioblastoma reflects cancer evolutionary dynamics. Proc Natl Acad Sci. 2013;110(10):4009-14. doi:10.1073/pnas.1219747110.

28. Jellum E, Andersen A, Lund-Larsen P, Theodorsen L, Orjasaeter H. Experiences of the Janus Serum Bank in Norway. Environ Health Perspect. 1995;103 Suppl 3:85-8.

29. Wibom C, Späth F, Dahlin AM, Langseth H, Hovig E, Rajaraman P et al. Investigation of established genetic risk variants for glioma in pre-diagnostic samples from a population based nested case control study. Cancer Epidemiol Biomarkers Prev. 2015. doi:10.1158/ 1055-9965.epi-14-1106.

30. Ekstrøm PO, Bjørge T, Dørum A, Longva AS, Heintz K-M, Warren DJ, et al. Determination of hereditary mutations in the BRCA1 gene using archived serum samples and capillary electrophoresis. Anal Chem. 2004;76(15):4406-9. doi:10.1021/ac049788k.

31. Bjørheim J, Gaudernack G, Giercksky K-E, Ekstrøm PO. Direct identification of all oncogenic mutants in KRAS exon 1 by cycling temperature capillary electrophoresis. ELECTROPHORESIS. 2003;24(1-2):63-9. doi:10.1002/elps.200390032.

32. Paez JG, Jänne PA, Lee JC, Tracy S, Greulich H, Gabriel S, et al. EGFR mutations in lung cancer: correlation with clinical response to gefitinib therapy. Science. 2004;304(5676):1497-500. doi:10. 1126/science.1099314.

33. Lafky JM, Wilken JA, Baron AT, Maihle NJ. Clinical implications of the ErbB/epidermal growth factor (EGF) receptor family and its ligands in ovarian cancer. Biochimica et Biophysica Acta (BBA) Reviews on Cancer. 2008;1785(2):232-65. doi:10.1016/j.bbcan. 2008.01.001.

34. Tomas A, Futter CE, Eden ER. EGF receptor trafficking: consequences for signaling and cancer. Trends Cell Biol. 2014;24(1):2634. doi:10.1016/j.tcb.2013.11.002.

35. The Cancer Genome Atlas Research N. Comprehensive genomic characterization defines human glioblastoma genes and core pathways. Nature. 2008;455(7216):1061-8. doi:10.1038/nature07385.

36. Yan M, Parker BA, Schwab R, Kurzrock R. HER2 aberrations in cancer: implications for therapy. Cancer Treat Rev. 2014;40(6): 770-80. doi:10.1016/j.ctrv.2014.02.008.

37. Andersson U, Guo D, Malmer B, Bergenheim AT, Brännström T, Hedman $\mathrm{H}$, et al. Epidermal growth factor receptor family (EGFR, ErbB2-4) in gliomas and meningiomas. Acta Neuropathol. 2004;108(2):135-42. doi:10.1007/s00401-004-0875-6.

38. Ose J, Schock H, Tjønneland A, Hansen L, Overvad K, Dossus L et al. Inflammatory markers and risk of epithelial ovarian cancer by tumor subtypes: the EPIC cohort. Cancer Epidemiol Biomarkers Prev. 2015. doi:10.1158/1055-9965.epi-14-1279-t.

39. M Q. Epidermal growth factor receptor serum levels and prognostic value in malignant gliomas. Tumori. 2007;93(3):275-80.

40. Ferri C, Sebastiani M, Giuggioli D, Colaci M, Fallahi P, Piluso A, et al. Hepatitis $C$ virus syndrome: a constellation of organ- and nonorgan specific autoimmune disorders, B-cell non-Hodgkin's lymphoma, and cancer. World J Hepatol. 2015;7(3):327-43. doi:10. 4254/wjh.v7.i3.327.

41. Acquaviva J, Jun HJ, Lessard J, Ruiz R, Zhu H, Donovan M, et al. Chronic activation of wild-type epidermal growth factor receptor and loss of Cdkn2a cause mouse glioblastoma formation. Cancer Res. 2011;71(23):7198-206. doi:10.1158/0008-5472.can-11-1514.

42. Dawson JP, Berger MB, Lin C-C, Schlessinger J, Lemmon MA, Ferguson KM. Epidermal growth factor receptor dimerization and activation require ligand-induced conformational changes in the dimer interface. Mol Cell Biol. 2005;25(17):7734-42. doi:10. 1128/mcb.25.17.7734-7742.2005. 